rooms, one for developing photographs, one for visual observations, and one for X-rays. The ordinary table for X-ray observations has been modified for work on anæsthetised animals. An ultra-microscope is installed in the room devoted t) research on colloids. On the north side of the second floor are rooms for microscopic and experimental neurology. Three rooms are specially fitted for blood gas analysis. The laboratory also contains a large library well supplied with physiological books and periodicals.

The class-rooms occupy the fourth and fifth floors; there are two large experimental rooms, one for elementary and the other for advanced work, and a histology room with places for ${ }_{5} 50$ students. Adjoining is a small demonstration room, holding about fifty, and on the first floor is a larger demonstration room, holding about eighty. This latter room has dark blinds, moved up and down by a motor, which can be set in action from the lecturer's table. It is fitted with epidiascope and with kinematograph.

The architect of the building is Sir Thomas Jackson. In the wing to be built later on the north side wil come the large lecture room and some additional rooms and offices.

\section{ORNITHOLOGICAL NOTES.}

TO the February number of British Birds the Rev. F. C. R. Jourdain and Mr. Clifford Borrer contribute an article on erythrism in the eggs of British species, that is to say, eggs in which the normal type of colouring has been replaced by one in which the markings are of various shades of red or reddish brown; in other words, those in which the pigment consists solely of oörhodein; but the range of colourvariation in the species includes eggs coloured with bile-pigment (biliverdin), either alone or with other pigment, to form the various greens and blues. For this reason the eggs of the Accipitres, which, although really erythristic, seldom show traces of other colouring matter, are excluded. As might have been expected, the erythristic variation generally extends to the entire clutch. Whether individual birds which lay erythristic eggs in one season, do so always, is a point to which no reference is made.

In the Selborne Magazine for February members of the Committee for the Economic Preservation of Birds direct attention to species of which the plumage may be used without involving any destruction other than would normally occur, as in the case of gamebirds, or without any destruction at all, as in the case of the ostrich, rhea, and, it is said, the peacock. On the other hand, it is urged that the slaughter of mischievous species, like many of the grain-eating parrots, is justifiable, and therefore that their plumage may be worn.

The feature of the winter number (1913) of Bird Notes and News is a coloured plate by Mr. Lodge of some of the species most severely persecuted by the plumage-trade. Statistics of the numbers of skins of various species offered at the London auctions are given, in connection with the Plumage Bill.

Bird-Lore (D. Appleton and Co., Harrisburg and New York) for January and February is a good number, containing two coloured plates, and the fourteenth annual census of the local migrations of wellknown American species. One of the results is to show that during the past season "chickadees," which seldom come so far south as Massachusetts, reached Rhode Island, Connecticut, and Rhinebeck.

From a paper by $\mathrm{Mr}$. H. Victor Jones in the February number of the Zoologist on certain paraNO. 2330, VOL. 93$]$ sites of birds, we learn that while rooks and the diurnal birds-of-prey-probably owing to the strength of their gastric juices-are practically free from intestinal infestations of this kind, curlews show, on the average, no fewer than 49.5 per head. As there seems to be a connection in many species between the numbers of external and internal parasites, it is suggested that some of the former may serve as hosts for the latter during the earlier stages of their development.

As one of the results of bird-protection, there are hopes that kites may soon be seen in districts from which they have long since disappeared. During the last few years these birds have increased considerably in numbers in Wales, and it is probable that the pair recorded by Messrs. Hale and Borrer in the March number of British Birds to have bred in Devonshire in the spring of $19{ }^{1} 3$ were emigrants from that colony. Kites are also recorded in the same issue, on more or less satisfactory evidence, to have been seen during $\mathrm{I}_{1} \mathrm{I}_{3}$ in Somersetshire, Derbyshire, and Buckinghamshire.

According. to the January number of the Emu, it is expected that an Act for the reservation of 300 acres to serve as a bird-sanctuary in Kangaroo Island will be passed by the Commonwealth Government next session. Lyre-birds, formerly abundant in very similar country in the Blackall Ranges, would probably flourish there. It is also recorded that at the annual congress of the R.A.O.U. a resolution was unanimously carried calling on the Government to pass a local Act on the lines of the British Plumage Prohibition Bill.

In the Field of March $28 \mathrm{Mr}$. Seth Smith directs attention to the remarkable cry uttered by the king penguin in the Zoological Gardens. The bird is shy of going through the performance, but if gently stroked on the throat by its keeper will gradually raise its head and stretch its neck to the utmost, then, throwing out its chest, it emits a series of loud, trumpeting sounas which last for some seconds; the bird on the utterance of the last note suddenly drops its head, as if bowing to the audience. The "song" and the concluding gesture are probably the "display" of the penguin, for in bowing it exhibits to the best advantage the brilliant golden patches on the sides of the head. 'As these patches are not confined to the male sex, it is probable that both sexes "display."

The feeding habits of the South African groundhornbill (Bycanistes buccinator), as exemplified in a pair of tame specimens, form the subject of a note by Mr. C. F. M. Swynnerton in the Journal of the South African Ornithologists' Union for December, I9I3. Their extreme voracity, the lightning-like rapidity with which they would seize rats in a barn, and the small size of many of the insects upon which they fed, were some of the most noticeable features of these great birds. After devouring half a score of rats at one meal, these birds would be ready for a second meal an hour later; and they would seize and eat house-flies with the same apparent zest as they devoured rats.

The beaiss of crossbills are not always crossed in the same manner, the upper half in some individuals crossing to the bird's own right, while in others the reverse condition obtains. Examination of I7 I specimens has enabled Mr. Miller Christy to state, in the April number of British Birds, that, so far as this evidence goes, the numbers of the two types are approximately equal-eighty-four of one type and eighty-three of the other, with four specimens indeterminable. This, it is suggested, is an indication that the crossing of the beak is of recent origin, and therefore probably not a Mendelian feature. 
The following extract is from a letter received by the editor from the London correspondent of the North Queensland Gazette, relating to an alleged remarkable habit on the part of those birds of paradise commonly known as rifle-birds (Ptilorhis) :--

"The birds collect sloughed snake-skins for use in connection with their nests. When the construction of the nest is finished, they place these skins around the outside of the structure in such a natural manner as to convey the impression to a casual observer that a living snake is coiled there. . . . A hawk, eagle, or crow, observing what it takes to be a nest with a snake coiled about it, is not likely to desire closer acquaintance."

R. L.

\section{THE ROYAL CANADIAN INSTITUTE.}

FSTABLISHED in 1849 at Toronto, then Upper E Canada, through the energy and activity of a rising young engineer, Mr. (now Sir) Sandford Fleming, as secretary, the "Canadian Institute" was incorporated by Royal Charter on November 4, I85x, and the title "Royal" has recently been conferred upon it. From the first this institute discussed questions and published memoirs of world-wide interest, under the able guidance of men of the type of Sir Sandford Fleming, Kivus Tully, Sir William E. Logan, E. Billings, Henry Youle Hind, Thomas Ridout, J. C. Browne, and others.

The objects of incorporation included the encouragement and general advancement of all the sciences, arts, and manufactures; in fact, for promoting all branches of knowledge dealing with the resources and development of a new country, not forgetting industrial productions and commerce, besides the establishment of a museum to promote the purposes of science and the general interests of the society. For sixty-five years these objects have been pursued by the institute, and with a membership of sixty-four in 1850 , the number has increased to nearly 400 . The institute has published volumes of Transactions that are a credit to its good name, both in its earliest days and of recent date. The institute has also materially assisted Sir Sandford Fleming in his publications on the zone system of time reckoning, which has been adopted the civilised world over. In its library there is found excellent reference material in many departments of special research work. In rgr $_{3}$ the number of exchanges received by the Royal Canadian Institute was 2 r 80 , whilst the publications received annually now reached 4000 . Weekly meetings take place during the season, when leaders of thought in science, history, and literature are invited to take part in the reading of papers, and delivery of lectures. These meetings are open to the public.

It was on April 2 of this year that the title "Royal" was conferred on the Canadian Institute of Toronto by his Majesty King George V., recognition of the same having been intimated to the institute through his Royal Highness Field-Marshal the Duke of Connaught, Governor-General of Canada. Besides sending a personal message to his Honour, Sir John Gibson, Lieutenant-Governor of Ontario, conveying his warmest congratulations to the Royal Canadian Institute on the recognition and honour conferred upon them by H.M. the King, his Royal Highness showed his interest in the institute and its progress by accepting the post of patron. A communication was read from Sir Sandford Fleming (Ottawa), and congratulatory speeches and addresses were given, in which Sir Edmund Walker, President Falconer, Principal Peterson, Dr. Coleman, F.R.S., and the presiding officer, Mr. Frank Arnoldi, K.C., took part. Sir Sandford Fleming was unanimously elected honorary president of the new "Royal Canadian Institute," and his three sons, Sandford, Walter, and Hugh, were formally elected members under the new title.

H. M. АмI.

\section{THE CAMBRIDGE "PREVIOUS" EXAMINATION.}

THE syndica e appointed by the Senate on May 9, I) 13 , to "consider what changes, if any, are desirable in the regulations relating to the Previous Examination, in the mutual relations of the Previous Examination and the examinations held by the Highest Grade. Schools Syndicate and the Local Examinations and Lectures Syndicate," has reported on somewhat drastic lines.

The syndicate has considered carefully the regulations and arrangements for the existing Previous Examination, and other examinations which are accepted as exempting from the Previous Examination, and has consulted the representatives of the Board of Education, the Headmasters' Conference, the Incorporated Association of Headmasters, and the Assistant-masters' Association, as well as certain members of the University of Oxford, who are concerned with analogous inquiries.

Two hundred headmasters of public and secondary schools sent replies to questions which were addressed to them by the syndicate. The syndicate is of opinion that the existing Previous Examination is an unsatisfactory test, and is not adapted to the present situation in secondary education, and it therefore recommends the introduction of changes, both administrative and educational.

The administrative change advocated is the establishment of a new syndicate which shall be called the Examinations Syndicate, which would take over the work of the present Local Lectures and Examinations Syndicate, so far as examinations are concerned, and of the Highest Grade School Examinations Syndicate. The new syndicate would control the whole of the "pass" examinations of the University.

The educational changes, proposed in the report, endeavour to coordinate the examinations which qualify for study at the University with the entrance examinations to the various professions; and throughout the deliberations the scheme of the Board of Education which is designed to assist such coordinations has been kept in view.

The syndicate proposes to abolish the distinction which now exists between the examination for candidates for honours and that for the "pass" degree. The additional subjects will be done away with.

The compulsory subjects which remain are divided into three groups, each of which may be taken separately. The first group consists of languages; two papers will be set in each of the following :Latin, Greek, French, and German. Greek is no longer to be compulsory, but Latin must be one of the languages offered.

The second group consists of mathematics and science: algebra and arithmetic, geometry, physics, and chemistry, or experimental mechanics.

The third group consists of English: essay and puecis writing, selected books, and outlines of English history.

The examination will be held four times a year at Cambridge only.

The report wili be discussed by the Senate at the beginning of the October term. So far as can be gathered, the resident opinion is in general favourable to its findings, though there is sure to be some criticism as to detail by the much-enduring college tutors who will find the task of entering their pupils complicated. 